HEALTH INSURANCE STATUS AND PHYSICIANINDUCED DEMAND FOR MEDICAL SERVICES IN GERMANY: NEW EVIDENCE FROM COMBINED DISTRICT AND INDIVIDUAL LEVEL DATA

Hendrik Jürges

(c) Mea-Mannheim Research Institute for the Economics of Aging 


\title{
Health insurance status and physician-induced demand for medical services in Germany: new evidence from combined district and individual level data
}

Hendrik Jürges

Version 1.2: March 2007

MEA-Universität Mannheim

L13,17

68131 Mannheim

Germany

Email: juerges@mea.uni-mannheim.de

Fax:+49-621-181-1863

\begin{abstract}
Germany is one of the few OECD countries with a two-tier system of statutory and primary private health insurance. Both types of insurance provide fee-for-service insurance, but chargeable fees for identical services are more than twice as large for privately insured patients than for statutorily insured patients. This price variation creates incentives to induce demand primarily among the privately insured. Using German SOEP 2002 data, I analyze the effects of insurance status and district (Kreis-) level physician density on the individual number of doctor visits. The paper has four main findings. First, I find no evidence that physician density is endogenous. Second, conditional on health, privately insured patients are less likely to contact a physician but more frequently visit a doctor following a first contact. Third, physician density has a significant positive effect on the decision to contact a physician and on the frequency of doctor visits of patients insured in the statutory health care system, whereas, fourth, physician density has no effect on privately insured patients' decisions to contact a physician but an even stronger positive effect on the frequency of doctor visits than the statutorily insured. These findings give indirect evidence for the hypothesis that physicians induce demand among privately insured patients but not among statutorily insured.
\end{abstract}

Keywords: supplier-induced demand, health care utilization

\section{JEL-Classification: I1 1}

Acknowledgements: I am grateful to Martin Salm for helpful comments. I am also greatly indebted to Dr. K.H. Wacker, Gummersbach, for raising my interest in this topic and providing anecdotal evidence. 


\section{Introduction}

This paper analyses the effects of individual health insurance status and local physician density (the number of physicians per 100,000 inhabitants) on the individual number of doctor visits in Germany, using data from the 2002 German Socio-economic Panel (SOEP). The paper contains three innovations compared to earlier analyses based on earlier waves of the same data set: first and foremost, I estimate separate count data models for respondents insured in the German statutory health insurance system and privately insured respondents. This is important because, although fees-for-service are generally fixed for patients in either type of health insurance, they are more than twice as large for privately insured patients. Physicians thus have a stronger incentive to induce demand among this patient type. Second, I use district (Kreis-) level information on physician density (Germany is divided into 439 districts). The information used in earlier studies was much coarser, and thus less likely to capture the physician density that is relevant for the demand for doctor's services. ${ }^{1}$ The third innovation is the use of an instrumental variable approach to account for the potential simultaneity of physician density. In principle, the first stage of the IV-approach models physician's location decisions and thus the (aggregate) supply of ambulatory health care services.

Physicians have the opportunity to induce demand because - as in other markets for credence goods such as car repairs or home maintenance - there are significant information asymmetries in the medical market. ${ }^{2}$ Doctors are generally better informed about necessary and appropriate diagnoses and treatments than their patients. After all, this is the very reason why patients visit doctors, and exactly because doctors are better informed, it is their duty to induce demand by informing patients about necessary and appropriate next steps in the treatment of some disease. It is not the fair-minded attempt by the physician to convince a patient of the necessity of some particular diagnostic test or treatment that health economists have in mind when they talk of demand inducement. Rather, to talk of physician induced demand, tests and treatments must not be medically indicated (including flat-of-the curve medicine) and doctors must suggest them only for profit and not for medical reasons. The question whether physicians systematically induce demand is contentious. Probably there is no health care system without incentives for demand inducement, and many people may once or twice have had the odd feeling that some diagnostic test or treatment was not strictly

\footnotetext{
${ }^{1}$ For instance, Pohlmeier \& Ulrich (1995) and Cassel \& Wilke (2002) use physician density on the state level. West Germany (until 1990) had 11 states. Post-unification Germany has 16 states.

${ }^{2}$ See Dullek and Kerschbamer (2006) for a unifying review of the economic theory of credence goods.
} 
necessary, but the important question is whether physician demand inducement is such a widespread and significant phenomenon that it should instigate public intervention.

Physician density is probably the most commonly used variable in empirical studies of physician-induced demand for health care services. Given the number and the average health level of patients in a specific region, a higher physician density implies a shift of the aggregate supply curve. Demand for medical services per physician decreases. When fees for health care services are fixed, as this is the case in Germany, physicians cannot respond to less demand by lowering their fees. Instead, they need to try to increase demand for their services, both in terms of quality and quantity. A positive correlation between physician density and health care utilization then indicates potential market problems. However, an alternative explanation for a positive correlation between physician density and doctor visits is that a higher physician density entails lower patients' opportunity costs of doctor visits, both in terms of travel costs and shortened queues in the physician's offices.

The empirical evidence on demand inducement is ambiguous. Early studies that find positive effects of physician density on health care utilization in an instrumental variables approach (simultaneity of physician density arises if one assumes that doctors tend to locate where demand is high) are for example Fuchs (1978), Wilensky \& Rossiter (1981), and Cromwell \& Mitchell (1986). In his classical article, Fuchs (1978) showed that a 10 percent increase in the surgeon/population ratio results in a three percent increase in the number of operations. Wilensky \& Rossiter find an elasticity of 0.1 between physician density and the frequency of follow-up visits to doctor's offices, and Cromwell \& Mitchell find a surgery rate elasticity with respect to surgeon concentration of 0.09 . However, evidence against the inducement hypothesis was also found e.g. by Sweeney (1982), McCarthy (1985), and Stano (1985) for the US, or Carlsen \& Grytten (1998) for Norway.

The early studies have been criticized because they provide at most indirect evidence (Dranove \& Wehner, 1994) or because the particular identification strategy was considered inappropriate or flawed (e.g. Auster \& Oaxaca 1981, Dranove \& Wehner, 1994). A few recent studies provide more direct evidence that corroborates the demand inducement hypothesis. For instance, several studies show that physicians react to exogenous changes in reimbursement rates (and hence exogenous changes in income) in a way that is consistent with demand inducement: output (the number of visits) increases when reimbursement is reduced, and vice versa (Rice 1983, Yip 1998). Gruber \& Owings (1996) use the exogenous decline in birth rates (in the 1970s and 80s) and hence exogenous decline in the income of 
obstetricians and gynecologists to explain a substantial increase in the proportion of caesarean deliveries. Moreover, they find a higher cesarean section rates for mothers with private health insurance than for women covered by Medicaid or without coverage (also see Stafford 1990) and even a larger increase in cesarean section rates in response to birth rate declines for privately insured than for other mothers. These findings are noteworthy because relative remuneration for cesarean delivery was much higher for the privately insured than for the publicly insured or the uninsured.

Empirical studies of demand inducement in Germany using a variety of data sources include Krämer (1981), Breyer (1984), Pohlmeier \& Ulrich (1995), Cassel \& Wilke (2002), Thode et al. (2004), and Kopetsch (2007). Here the evidence is also mixed. Krämer (1981) uses regional-level administrative data of statutory health insurances from the early 1970s and finds that the number of doctors in region has a twice as large effect on aggregate health care expenditures than the number of patients. This finding is consistent with demand inducement. Breyer (1984) uses administrative data provided by the largest German statutory health insurance $(\mathrm{AOK})$ and estimates separate single-equation models for regions with a low and high physician density. Although he finds a positive relationship between local physician density and health care expenditures in both regressions, the gradient is steeper at low initial levels of physician density than at high initial levels, which (in the light of a specific theoretical model), is interpreted as evidence for an availability effect rather than an inducement effect. Kopetsch (2007) uses detailed physician claims data and finds negative effects of physician density on the average number of patients but positive effects on average treatment intensity.

Pohlmeier \& Ulrich, Cassel \& Wilke, and Thode et al. combine survey data on individual health care utilization with regional information on physician density. Pohlmeier \& Ulrich use 1985 SOEP data to estimate hurdle models, which separate the individuals' contact from their frequency of contact decisions. They find no effect of physician density on the probability of contacting a family doctor but significant positive effects on the number of family doctor visits. Since the former probability can be viewed as purely demand driven but the second combines demand and supply evidence, this finding is interpreted as evidence for demand inducement and against the availability hypothesis. Cassel \& Wilke use ECHP and SOEP data for several years in the 1980s and 1990s and find no effects of physician density on the probability and frequency of doctor visits. The same holds for Thode et al who use data from the German health interview surveys. 
The major drawback of the first set of studies is that they provide evidence only on patients insured in the statutory health care system while those who are privately insured are ignored due to data limitations. However, as is shown below, the distinction is vital because of fundamentally different incentives in the two insurance systems. One shortcoming of the latter set of studies is that physician density is measured on the state (Bundesland) level. Estimates could be biased downwards because this information is too coarse to reflect the relevant regional market for health care services. In particular for family doctors, the relevant market is likely to be much smaller, probably on the town or in the case of larger cities even on the neighborhood level. Non-findings can thus be explained by measurement error in the main explanatory variable. Moreover, none of the above studies for Germany accounts simultaneously for both alternative explanations for the positive physician density-health care utilization: reverse causation and availability effects.

This paper is an attempt to remedy the above shortcomings by using data on physician density on the district level, by explicitly modeling supply or doctors' location decisions, by estimating negative binomial hurdle models and thus analytically separating contact and frequency decisions, and by providing separate analyses for respondents with different insurance status (statutory vs. private). The paper is organized as follows. Section 2 gives the institutional background by briefly describing some salient features of the German health care system. Section 3 describes the conceptual framework of this study. The data are described in Section 4. After motivating the identification strategy chosen in this paper, Section 5 contains the regression results. Section 6 gives a summary and conclusion.

\section{Institutional background: insurance, fees, and incentives}

About 90 percent of the German population are insured in the German statutory health insurance system (SHI), see Colombo \& Tapay (2004). SHI is financed by payroll taxes or contributions. Contribution rates are independent of individual health risks and provide coverage not only for the insured but also for non-employed dependents. In 2002, the SHI system consisted of 350 different insurers or sickness funds, but services covered were (and still are) highly regulated, so that there was no effective competition between them. SHI provides free ambulatory care from family doctors and specialists - only in 2004 a copayment of $€ 10$ per quarter has been introduced. ${ }^{3}$ Physician's remuneration follows a fixed

\footnotetext{
${ }^{3}$ During most of 2002, the Euro-US-Dollar exchange rate was about one-to-one.
} 
fee-for-service schedule. ${ }^{4}$ For instance, in 2002, a short family doctor consultation (of less than 10 minute length) earned about $€ 5.60$, and an ECG earned about $€ 8.80$. The $€ 5.60$ are actually earned only for the 'first' consultation 'case', i.e. once per patient per quarter. Followup (short) consultations in the same quarter yield only about $€ 1.35$. Another noteworthy feature of the SHI system is that doctors are paid directly by the insurers. Patients never learn how much doctors actually charge for their services and have no idea about the (marginal) costs of treatment. Willingness to pay is thus no barrier to "unproductive" treatments. Overall, the SHI system as such provides no incentives to physicians and patients to restrict the treatment to the medically necessary and to contain costs.

--- about here Figure 1 ---

Tenured civil servants, the self-employed, and employees who are above a certain gross annual income threshold (€40,500 in 2002) are allowed to opt out of SHI and purchase insurance in the private health insurance system (PHI), also see Figure $1 .^{5}$ In 2002, about 50 insurance companies offered private health insurance. In contrast to the statutory health insurers, private insurers offer a choice of contracts with different combinations of services covered and deductibles. Physicians are paid directly by the patients who later get reimbursed by their insurance. Patients who do not send in a claim during the course of a calendar year usually get a rebate on their annual premium.

Opting out of the SHI system is attractive because private insurance premiums which are independent of income - are on average lower and more services are covered than in the SHI. ${ }^{6}$ Premiums are lower because PHI has a much better risk pool than SHI. This is not only due to the legal access constraints that effectively allow only better than average health risks to join PHI. In contrast to SHI, private health insurers are allowed to differentiate fees by age and sex (women pay more), to take individual risk premiums, and to reject bad risks. Thus bad risks are systematically kept out of PHI risk pool. The opting out decision is usually a one in a life-time decision (thus contracts are renewed year by year). Only employees who become unemployed or whose income falls below the threshold are allowed to return to the SHI system. The two main drawbacks of taking out private health insurance in Germany are (1) insurance for non-employed dependants is not free and (2) insurance

\footnotetext{
${ }^{4}$ Each service is awarded a specific number of points that reflects the relative value of this service. The value of one point varies across regions and over time. In 2002, one point earned approximately 4 Cent.

${ }^{5}$ About 10 percent of the population are privately insured. Less than 0.5 percent of the population have no health insurance.

${ }^{6}$ This holds especially for tenured civil servants. Another particularity of the German health care system is that the state covers half of the civil servants' health care costs, so that civil servants only need to buy private health insurance with $50 \%$ coverage.
} 
premiums can rise considerably over time and with age, depending on the development of the particular risk pool of an insurer. ${ }^{7}$

Insurance status (statutory vs. private) potentially affects the demand for and supply of health care services in Germany. Patients with a private health insurance are attractive from the doctors' viewpoint because they can be charged much higher (but still legally fixed) fees for the same services as SHI patients. Remuneration for services to privately insured patients follows a similar fee-for-service schedule as remuneration for services to the statutorily insured. In 2002 , the 'basic fee' was $€ 5.66$ for a short family doctor consultation and $€ 8.86$ for an ECG (thus pretty much the same as for the same services rendered to SHI insured patients). However, physicians are allowed to charge up to 2.3 times the basic fee if a case is more difficult than usual and up to 3.5 times the basic fee in special cases. In practice of course, physicians always charge at least 2.3 times the basic fee. ${ }^{8}$ A short family doctor consultation of a privately insured patient thus earns about $€ 13$ and an ECG earns $€ 20.78$ (compared to $€ 5.60$ and $€ 8.80$ for a statutorily insured patient). Similar relationships hold for all other services. Utility maximizing physicians thus face a kinked budget constraint which would make it rational to first serve all privately insured patients if that was feasible. In fact, privately insured patients get preferential treatment at some doctors' offices, for instance by getting appointments much quicker than others, buy jumping queues at the doctors offices, or by more comfortable waiting rooms. Older physicians also often choose some kind of semiretirement by treating only private patients. Moreover, if physicians induce patients to demand services beyond the medically indicated level, they behave rationally if they do so primarily for the privately insured (if necessary at the expense of patients in the statutory health insurance).

\section{Conceptual framework}

In this section, I will briefly outline the conceptual framework that motivates the empirical analysis. Individual health care utilization is assumed to be determined by supply and demand factors in a multi-stage process (cf. Manning et al. 1981). Here, we consider a four-stage model. In the first stage, doctors choose locations for their practices. In the second stage, patients contact doctors. In the third stage doctors recommend treatments and in the

\footnotetext{
${ }^{7}$ A full analysis of individual insurance choice is beyond the scope of this paper. To my knowledge, there is only one microeconometric study so far (Rohweder 1995).
} 
fourth stage, patients decide whether to comply with the recommendation. I will describe each stage in turn and discuss the role of physician density and patients' insurance status.

Doctors choose the location that maximizes their expected utility, which is a function of income, leisure, 'psychic' inducement costs, and location-specific amenities (location decision). Income depends positively on the number of patients - which in turn is a function of physician density and the average health level of the local population - and on the proportion of privately insured patients. Leisure depends negatively on the number of patients but not on the proportion of privately insured patients. Everything else equal, physicians prefer regions with a large proportion of ill persons and regions with a large proportion of privately insured patients.

In the second stage, patients who feel ill decide whether to contact a physician in their region (contact decision). Whether a patient feels ill within a specific period can be viewed as the outcome of a random process that is influenced by a patient's health status. Whether a doctor is contacted when a patient feels ill depends, among other things, on the local physician density. A higher physician density reduces the patient's cost and thus increases the probability of a patient-doctor contact. But ceteris paribus, a higher physician density decreases the number of contacts per physician, so that the net effect of higher physician density on the number of initiated contacts per physician is unclear. Whether patients contact a doctor should also depends on insurance status. As mentioned in the preceding section, privately insured patients may have lower opportunity costs of visiting a doctor because they get preferential treatment. On the other hand, the privately insured are discouraged from visiting a doctor for minor ailments because of deductibles and rebates.

In the third stage, the physician informs the patients about their health status and suggests some treatment (intensity). The medically indicated treatment intensity is determined solely by the patients' true (latent) health status. Note that neither the number of patients who initiate contact, nor the private-statutory mix of those who initiate contact, nor the indicated treatment intensity can be influenced by the physician once the practice location is chosen. It is at this stage when the physician has the opportunity to induce demand. Consider the following simple model (largely borrowed from Gruber \& Owings (1996)):

Since the physician's location is already fixed at this stage, we neglect location specific capital. Let physician utility be given by the additive separable function $U=u(Y)-v(I)$ with

\footnotetext{
${ }^{8}$ The fact that PHI insurance premiums are on average lower than SHI contributions although treatments of the privately insured cost more than twice as much reflects how unequal risks are distributed between the two systems.
} 
$\mathrm{u}^{\prime}>0, \mathrm{u}^{\prime \prime}<0, \mathrm{v}^{\prime}>0$ and $\mathrm{v}^{\prime \prime}>0$, and where $\mathrm{Y}$ denotes full income (earnings minus the value of forgone leisure) and I is total inducement,. Function $v$ reflects the physician's disutility from inducement. Income equals fees-for-service times the number of services provided: $\mathrm{Y}=\mathrm{Y}_{\mathrm{P}} \mathrm{P}+\mathrm{Y}_{\mathrm{S}} \mathrm{S}$, where $\mathrm{P}$ and $\mathrm{S}$ denote services to privately and statutorily insured patients, respectively. $Y_{P}$ and $Y_{S}$ are the respective (exogenous) fees with $Y_{P}>Y_{S}$. In the following, we normalize $Y_{S}$ to one, hence $Y_{P}>1$. $P$ and $S$ are determined by the number of contacts $C$, the proportion of privately insured patients $\pi$, and the amount of inducement per patient $\mathrm{i}$ : $\mathrm{P}=\pi \mathrm{C} \mathrm{f}\left(\mathrm{i}_{\mathrm{P}}\right)$ and $\mathrm{S}=(1-\pi) \mathrm{C} \mathrm{f}\left(\mathrm{i}_{\mathrm{S}}\right)$. The inducement function $\mathrm{f}$ is increasing and concave with $f(0)=1$. If the function was linear, it would be optimal to sell services only to privately insured patients. Total inducement equals the aggregate amount of inducement per patient: $I=\pi C i_{P}+(1-\pi) C i_{S}$. Finally, $i_{P}$ and $i_{S}$ are assumed to be non-negative. This assumption essentially means that doctors never reject or willingly undertreat patients that have contacted them. ${ }^{9}$

The physician chooses $i_{P}$ and $i_{S}$ to maximize $U$. The first order conditions are:

$$
\partial \mathrm{U} / \partial \mathrm{i}_{\mathrm{P}}=\mathrm{u}^{\prime} \mathrm{Y}_{\mathrm{P}} \pi \mathrm{C} \mathrm{f}^{\prime}\left(\mathrm{i}_{\mathrm{P}}\right)-\mathrm{v}^{\prime} \pi \mathrm{C} \leq 0 ; \mathrm{i}_{\mathrm{P}} \geq 0 ; \mathrm{i}_{\mathrm{P}} \partial \mathrm{U} / \partial \mathrm{i}_{\mathrm{P}}=0
$$

and

$$
\partial \mathrm{U} / \partial \mathrm{i}_{\mathrm{S}}=\mathrm{u}^{\prime}(1-\pi) \mathrm{C} \mathrm{f}^{\prime}\left(\mathrm{i}_{\mathrm{S}}\right)-\mathrm{v}^{\prime}(1-\pi) \mathrm{C} \leq 0 ; \mathrm{i}_{\mathrm{S}} \geq 0 ; \mathrm{i}_{\mathrm{P}} \partial \mathrm{U} / \partial \mathrm{i}_{\mathrm{S}}=0
$$

Let us consider only the interior solution with $i_{P}>0$ and $i_{S}>0$. Then the following optimality condition can be derived (where stars indicate optimal values):

$$
\mathrm{Y}_{\mathrm{P}} \mathrm{f}^{\prime}\left(\mathrm{i}_{\mathrm{P}} *\right)=\mathrm{f}^{\prime}\left(\mathrm{i}_{\mathrm{S}}^{*}\right)
$$

This condition states that the marginal income from inducing a privately insured patient must equal the marginal income from inducing a statutorily insured patient. $Y_{P}$ is greater than 1 , hence $i_{\mathrm{P}}{ }^{*}>\mathrm{i}_{\mathrm{S}} *$. Since fees for services to privately insured patients are higher than fees for services to statutorily insured, biased suggestions should be primarily given to the former type of patient. Comparative static analysis of the model shows that inducement per patient (private and statutory) decreases when $\mathrm{C}$ increases, i.e. when physician density falls. If physician density falls sufficiently or the relative fee for services to private patients $Y_{P}$ is sufficiently high, physicians might also find themselves at corner solutions with $i_{P}>0$ and $i_{\mathrm{S}}=0$ or with no inducement at all.

\footnotetext{
${ }^{9}$ Relaxing this assumption would provide an interesting extension of the model because it allows optimal solutions where doctors induce private patients' demand and simultaneously reject statutorily insured patients (or put them on long waiting lists). However, one would presumably also have to change the assumptions about the utility function, because deliberately not treating a patient will also cause disutility.
} 
In the fourth stage, patients decide about their compliance with the doctor's recommendation (also known as the frequency decision). The degree of compliance depends on the expected benefits and costs (direct and indirect) of treatment. Benefits are inversely related to patient's self-perceived health status. With regard to costs, similar arguments apply as in the contact decision stage: physician density reduces indirect costs by reducing travel and waiting times and privately insured patients have lower opportunity costs because of preferential treatment.

The empirical model estimated in this paper will not distinguish between the third and fourth stage of the process. With household survey data one usually observes only the joint outcome, i.e. the realized number of visits. The estimated model will consist of three equations, one for the first stage, explaining aggregate location choice, one for the second stage, explaining the probability of contact, and one joint equation for the third and fourth stages taken together (frequency decision).

\section{Data description}

The data used in this study combine survey data on individual health care utilization drawn from the 2002 wave of the German Socio-Economic Panel (SOEP) with indicators on the regional level, specifically on the Kreis (district) level, which were mainly drawn from the 2004 regional database (INKAR) of the Federal Office for Building and Regional Planning (BBR). In the following, I describe each data in turn.

\subsection{Individual level data}

SOEP respondents are asked to report the number of doctor visits during the last three months. The 2002 wave does not discriminate between family doctor and specialist visits. 31 percent of all SHI patients and 37 percent of PHI patients have not seen a doctor at all during these three months (see Figure 2). Nearly 80 percent of the sample visited a doctor three times or less. Only 3.5 percent of the sample reported more than 10 visits. The average number of physician visits in the SHI and PHI samples is 2.57 and 2.31, respectively, with standard deviations variances equal to 4.24 and 3.99, indicating substantial overdispersion. Conditional on visiting a doctor at least once, the average number of doctor visits was about 3.7 in both subsamples (only marginally larger for SHI patients). The number of visits is highly skewed. 
The explanatory variables in the working sample are described in Table 1, separately for SHI and PHI respondents. The full sample has 22,417 observations, of which 3,245 (14.5 percent) are privately insured. 40 percent of the privately insured have a deductible. ${ }^{10}$ As mentioned above, the proportion of privately insured individuals in the population is about 10 percent. Thus the privately insured are overrepresented in our data. One of the reasons to use the 2002 SOEP wave is that in this year, a supplement of high income households has been added to the SOEP. 44.2 percent of the individuals in this supplement were privately insured (compared 10.7 percent in the original sample), thus increasing the statistical power when separate regressions are run for SHI and PHI respondents.

--- about here Table 1 ---

The SHI and PHI subsamples differ in a number of important respects. In particular, privately insured respondent are in better self-rated health. 49 percent of the SHI sample, compared to 60 percent of the PHI sample, say they are in good or very good health, and 12 percent versus 10 percent have been in a hospital in the preceding year. Note that the health difference can be found despite the fact that the privately insured are on average nearly one year older. Still, as explained above, it is not surprising to find the privately insured sample in better health. In addition to the fact that they have most likely passed a health screening before taking out private health insurance, they are predominantly male, have nearly three years more formal education and much higher income. The median equivalent income in the SHI sample was $17,747 €$ compared to $30,282 €$ in the PHI sample. ${ }^{11}$ Among the privately insured, more people work full-time, and less people work part-time or do not work. Considering how selection into private health insurance works (see the minimum income threshold), this is not surprising either.

It should be noted that despite the fact that privately insured respondents are much healthier and wealthier, they visit doctors only slightly less often than respondents insured in the statutory health insurance. In fact the difference in the number of doctors visits is not statistically significant. Thus conditional on health, it appears as if physicians treat the privately insured more intensely. This issue will be analyzed in greater detail in Section 4.

\footnotetext{
${ }^{10}$ Privately insured respondents without deductible are found predominantly among civil servants. In their case, the employer pays at least 50 percent of the sickness costs, and only the rest needs to be covered by a private insurance. To the best of my knowledge, private insurers do not offer contracts with deductibles to civil cervants. Interestingly, the employer's part of the insurance has a deductible, but it does come by a completely different name (Kostendämpfungspauschale), so that many civil servants may actually not be aware of the fact that they have a deductible indeed.

${ }^{11}$ Individuals living in households with implausibly low income (<3600 Euro per year; 111 households) have been excluded from the sample.
} 


\subsection{District level data}

The bottom of Table 1 contains information on the district level. Of the 439 districts in Germany, the SOEP data covers 434. The INKAR 2004 database is a rich source of statistical information on the district level in Germany (for the year 2002). Physician density, measured as the number of physicians per 100,000 inhabitants, is the most interesting variable in the context of this study. ${ }^{12}$ It ranges from 70 (Saalkreis) to 383 (Heidelberg) with a mean of 150 and a standard deviation of 51 . We have thus sufficient regional variation in this variable for an informative empirical analysis.

As mentioned before, I use an instrumental variable approach to account for the potential simultaneity of physician density. Suitable instruments are variables that affect the location decision of physicians but have no direct effect on the number of doctor visits of individuals observed in the SOEP. The instruments used here are log income per capita in the district, the percentage of inhabitants aged 65 and over living in the district and whether the district has a medical school.

Data on the first two instruments are drawn from the INKAR database. Gross income per capita serves as a proxy for a whole host of amenities that make a particular region attractive in individual location decisions. Per capita gross income ranges from 11,300€ (Südwestpfalz, Zwickauer Land) to $80,600 €$ (München). Doctor density is expected to be higher in high income regions, for instance because high income regions might provide better employment opportunities for physicians' spouses, or better schools for physicians' children. The number of privately insured patients might also be higher, which offers better earning opportunities for physicians.

Since older individuals are on average less healthy and need doctors services more often, this variable indicates the aggregate demand for medical services in the population. It is assumed that doctors tend to locate where demand his relatively high. The average percentage of inhabitants aged 65 and over is 17.7. It has standard deviation 1.9 and it ranges from 12.4 (Freising) to 23 (Pirmasens). One argument that could be brought forward against this instrument is that the direction of causality might also go in the opposite direction: less healthy people tend to locate in regions where there is a large supply of medical services.

\footnotetext{
${ }^{12}$ The number of physicians includes those providing ambulatory services under contract of the regional doctors' association (Kassenärztliche Vereinigung). Such a contract is a necessary condition to treat patients insured in the German statutory health care system. Physicians who exclusively treat privately insured patients (less than $5 \%$ of all physicians providing ambulatory services) are thus not included here.
} 
However, given the low geographical mobility of older people, it seems unlikely that this is an important causal pathway.

The third instrument is a dummy variable that captures whether a medical school is located in the district. There are 43 such districts in Germany. The argument behind this instrument is that people are to some extent regionally immobile. Physicians in Germany who start practicing on their own are typically between 35 and 40 years old (cf. Kassenärztliche Bundesvereinigung 2003, Table I.21). Starting physicians will thus often have lived for a substantial number of years in or close to a city where a medical school is located and have built up location-specific capital, so that regional mobility tends to be low.

\section{Model estimation and results}

In order to separately estimate the contact and frequency decision stages, I follow Pohlmeier \& Ulrich (1995) and Gerdtham (1997) in computing negative binomial hurdle model. Hurdle models treat the decision to contact a physician at all and the decision how often to visit the physician can be treated as different stochastic processes. They consist of two parts, which can be estimated by separate maximizations of the likelihood functions (Mullahy 1986). In the first part of the model, our key variable physician density reflects the regional availability of doctors to patients. The second part of the model analyses the individual number of doctor visits only for those who visited a doctor at least once in the reference period. Only in this second part, a positive coefficient of physician density on the number of doctor visits is interpreted as evidence for physician induced demand. One advantage of hurdle model is that it allows the same variables to have effects of different signs on the contact decision and the frequency decision. ${ }^{13}$

Formally, the hurdle model is specified as follows (cf. Deb \& Trivedi 2006). Let the probability of positive counts (conditional on covariates $X$ ) be determined by some density function $f_{1}: \operatorname{Pr}[y>0]=1-\operatorname{Pr}[y=0]=1-f_{1}(0)$. The number of (positive) counts is determined by a truncated density function $f_{2}(y \mid y>0)=f_{2}(y) /\left(1-f_{2}(0)\right)$, which is multiplied by $\operatorname{Pr}[y>0]=1-f_{1}(0)$ to ensure that probabilities sum to one. The stochastic process of the hurdle model can then be written as

\footnotetext{
${ }^{13}$ This assumption can be tested statistically by comparing the log likelihood of the hurdle model (which is the sum of the two parts' log-likelihoods) with the log likelihood of a (single equation) negative binomial model. With the data used in this paper, the single equation model is clearly rejected.
} 


$$
g(y)=\left\{\begin{array}{cc}
f_{1}(0) & \text { if } y=0 \\
{\left[1-f_{1}(0)\right] f_{2}(y \mid y>0)} & \text { if } y>0
\end{array}\right.
$$

with log-likelihood function

$$
\log L=\sum_{y \geq 0} g(y)=\left(\sum_{y=0} \ln f_{1}(0)+\sum_{y>0} \ln \left[1-f_{1}(0)\right]\right)+\sum_{y>0} \ln f_{2}(y \mid y>0) .
$$

This shows that the log-likelihood function can be written as the sum of a binomial probability part (in parentheses) and a truncated count model part.

The meaningful distinction between contact and frequency of contact decision in a hurdle model entails two assumptions. First, there must not be more than one sickness spell within the reference period. Second, the first count in the reference period actually constitutes a first contact related to a sickness spell and not a follow-up visit belonging to sickness spell that started before the reference period. Of course, either assumption will almost certainly be violated in a few cases. How many cases are concerned obviously depends on the length of the reference period. The longer the reference period, the larger the number of multiple sickness spells but the smaller the probability that the first registered contact belongs to sickness spell from a preceding period, and vice versa. The optimal length of the reference period is a priori unclear, but the three months used in the SOEP appear to be fairly good compromise (cf. Pohlmeier \& Ulrich 1995, Gerdtham 1997).

\subsection{Instrumenting physician density}

To account for the potential simultaneity of physician density, I follow a two-step IVtype procedure (cf. Mullahy 1997, Winkelmann 2000). In the first step I predict physician density by OLS, using the three instruments described above: the average gross income in the district, the proportion of people older than 65 living in the district, and a dummy variable that indicates whether the district has a medical school. The predicted values are then used in the second step two-part model instead of the original value of physician density. Standard errors that account for the inclusion of estimated variables in the second step are computed by bootstrapping (repeating the full estimation procedure including first and second estimation steps 200 times).

Instrumental variables are always subject to close scrutiny. First, the instruments must not be weak, i.e. they must be sufficiently correlated with the endogenous regressor. A recently established rule-of-thumb criterion for good instruments is an F-statistic larger than 
10 in a test of joint significance in the first stage regressions (cf. Staiger \& Stock, 1997, but note that the rule-of-thumb was developed for the linear 2SLS model). On that account, my instruments perform quite well. Table 2 shows the parameter estimates and test results for the first step regressions, i.e. for the full sample and for the separate samples. Note that standard errors are cluster adjusted, i.e. they are computed as if the full sample regression contained only 434 observations (of districts). The F-statistics are larger than 55 and thus well above the threshold of 10 in all three models. Including the instruments in the first step raises the Rsquared by more than 60 percentage points, i.e. the instruments have substantial explanatory power.

--- about here Table 2 ---

In terms of their signs, the instrumental variables have the expected effects on physician density. Districts with higher per capita income, districts with a large proportion of older inhabitants, and districts with a medical school have a higher physician density than others. Only few of the individual level variables are significantly related with doctor density. Districts with a higher physician density are characterized by a lower proportion of married individuals, and a higher proportion of better educated, two variables that possibly reflect the degree or urbanization.

Another concern about instrumental variables is that the identifying (exclusion) restrictions may not hold. In the context of this paper, the exclusion restrictions hold if average district income, the percentage of individuals aged 65 and over living in a district, and the presence of a medical school do not directly affect the likelihood and frequency of doctor visits of an individual living in the district. If there is an effect, it must be only indirect, i.e. through the correlation of the instruments with physician density. This assumption sounds plausible, and although exclusion restrictions cannot be tested formally, one can at least check whether the instruments have an independent effect on the outcome variables by including them in the outcome regression along with the variable that is to be instrumented. The Chisquared statistics for the joint significance of the instruments in the two outcome equations are 3.40 and 3.53 (with 3 degrees of freedom), respectively, in the full sample, 3.17 and 3.04 in the SHI subsample, and 3.13 and 0.26 in the PHI subsample (detailed regression results not shown). The corresponding P-values are .33 and .32, .37 and.36, and .38 and .97. In other words, the instruments appear to have no independent effect on the probability of visiting a doctor and the number of doctor visits. 


\subsection{The probability of physician visits}

The first part of the hurdle model used to analyze the probability of contact is a logistic regression model. ${ }^{14}$ Results without and with correction for possible simultaneity of physician density are shown in Table 3. Let us begin with a discussion of the full sample results (column 1 and 2). A positive effect of physician density on the probability of contact is found regardless of whether physician density is instrumented. Assuming that the first contact is solely demand driven, the positive effect of physician density can be interpreted as the effects of reduced opportunity costs or increased availability. Without taking into account potential simultaneity, the logit coefficient of $\log$ physician density is about .15 and significant at the 1 percent level. The coefficient can be roughly interpreted as an elasticity, i.e. when physician density rises by 1 percent, the probability that a physician is contacted (conditional on heath and other covariates) rises by 0.15 percent. When simultaneity is taken into account, the effect size is only slightly smaller, but standard errors increase so much that the effect is no longer statistically significant even at the 5 percent level. However, the difference between both estimates is statistically insignificant, so that one cannot reject the null hypothesis that physician density is in fact exogenous. This holds not only for the logit model in the full sample but for all estimation parts in all samples. For this reason, I will restrict the following discussion to the standard regression results (but all IV-estimates are still shown for interested readers).

--- about here Table 3 ---

Privately insured respondents are less likely to have seen a doctor at all in the preceding three months. Note that this is conditional on observed health. ${ }^{15}$ Plausible explanations for this finding have been mentioned before. First, insurance status might reflect unobserved health status since private insurance companies are allowed to screen applicants and to reject bad risks. Second, in contrast to patients covered by the statutory health system, privately insured patients first pay the doctors bill and get reimbursed later (even if they have full coverage), i.e. they do not have the illusion of zero marginal costs. Deductibles and rebates should further discourage doctor visits for minor ailments. In fact, for patients with deductibles, the estimated probability of visiting a doctor is further reduced, but the difference to privately insured without deductible is statistically insignificant.

\footnotetext{
${ }^{14}$ This corresponds to the specication chosen by Gerdtham (1997). Pohlmeier \& Ulrich (1995) use a negative binomial model in the contact decision part of their estimations.

${ }^{15}$ Including more detailed health information (SOEP 2002 contains a variant of the SF12 questionnaire) does not change this result.
} 
When the sample is split into statutorily and privately insured individuals (see columns 3 to 6), an interesting picture emerges. Whereas the effect of physician density is still positive and significant in the SHI sample (with an elasticity of about 18 percent), it vanishes for privately insured patients. This means that demand for health care services of statutorily insured respondents is affected by changes in opportunity costs related to physician density but that the demand of the privately insured is not. This result is plausible because the privately insured can jump queues formed by the statutorily insured patients at some doctors' offices, an issue that often gives rise to health care equity debates in the German public. Again, the effect of deductibles on contact is negative but insignificant.

Let us also briefly discuss the effects of the other covariates. First note that with one exception (part-time employment), the estimated coefficients are very similar across samples and estimation methods. Moreover, they are mostly according to expectations and in line with earlier studies for Germany (e.g. Pohlmeier \& Ulrich, 1995). Expectedly, the largest effects on the decision to contact a physician can be found for self-rated general health and for hospital stays in the preceding year (as a more objective health indicator). The odds of visiting a doctor at least once are about 4.5 times larger for respondents in very poor self-rated health than for those in fair health (the reference category). Likewise, those in very good health have odds that are about one third as large as those of the reference category. ${ }^{16}$ Hospital stays in the preceding year lead to about 2.5 higher odds of physician contacts.

Conditional on all covariates, the probability of having visited a doctor in the last three months first decreases in age and then increases in age. The minimum is reached at about age 40. Women are substantially more likely to visit doctors even if self-rated health status is controlled for, and married individuals are more likely to contact doctors than others. This holds particularly for men, as the large interaction effect of marital status with sex reveals. Better educated and higher income individuals also show a higher likelihood of visiting a doctor. Since this effect is measured conditional on health, it might reflect the tendency of better educated and higher income individuals to care more for their health (higher allocative efficiency or stronger preferences for the future, cf. Grossman 2005). It might also reflect socio-economic inequality in access to health care (e.g. Gerdtham 1997). Full-time employed respondents are significantly less likely to contact a physician. which is probably largely a matter of opportunity costs. Part-time employees in the statutory health care system are also less likely to contact a physician than the reference group, whereas privately insured part-time

\footnotetext{
${ }^{16}$ Odds ratios are obtained by exponentiating the logit coefficients. In contrast to marginal effects obtained from probit regressions they are constant across different values of the other explanatory variables.
} 
employees are more likely, but the difference to respondents who are not working is not significant.

\subsection{The frequency of doctor visits}

The frequency of doctor visits is analyzed conditional on visiting a physician at least once in the last three months using the zero-truncated negative binomial model. Results for the different samples without and with correction for possible simultaneity of physician density are shown in Table 4.

Physician density has a significant positive relationship with the number of doctor visits. This holds in the full sample and in the two subsamples, independent of whether potential simultaneity is dealt with. Instrumenting physician density actually increases the point estimates, but as was mentioned above, the Hausman-test never rejects the null hypothesis of exogenous physician density. Since physician density enters the regression equation in logarithms, its coefficient can be interpreted as an elasticity. Thus a one percent increase in physician density raises the number of doctor visits among all respondents by 0.17 percent. Overall, the effect size is in the range of findings found in the US (e.g. Stano 1985, Cromwell \& Mitchell 1986).

Note that insurance status has a fundamentally different effect on the frequency of doctor visits than on the contact decision. While the privately insured are less likely to contact a doctor, their number of doctor visits is significantly larger than that of patients covered by statutory health insurance. If the privately insured are on average healthier, one can expect them also to visit their doctor less often. One possible explanation for this seemingly contradictory finding is that physicians treat privately insured patients differently. Just because the health services rendered to a privately insured individual pay so much better than the same services rendered to individuals insured in the statutory health insurance, physicians have an incentive to sell unnecessary diagnoses and ineffective treatments to the privately insured. Separating the sample by insurance status corroborates this interpretation. It reveals that the estimated effect among privately insured is about 1.6 times as large as among statutorily insured (with an. the elasticity of 27 versus 16 percent). The difference is not statistically significant, however, due to the large standard errors estimated for the privately insured.

--- about here Table 4 --- 
The frequency of physician visits given contact is assumed to be determined by demand as well as supply factors. Viewed in conjunction with the earlier results on contacts, which are assumed to be determined only by demand, I hence find indirect evidence against demand inducement among statutorily insured but for demand inducement among the privately insured. This is because (1) among statutorily insured patients the elasticity of the contact and the elasticity of the number of doctor visits with respect to physician density are of the same size, (2) the frequency elasticity is (statistically) larger than the contact elasticity among privately insured (at $\mathrm{p}<0.10$ ). This key results is illustrated in Figure 3, which shows the average predicted probability of physician contacts and the average predicted number of physician visits conditional on visiting, separately for privately and statutorily insured respondents.

--- about here Figure 3 ---

Let us also look at the effects of the covariates. Again, the estimates are fairly similar across samples and specifications. Health itself has the expected strong impact on the frequency of doctor visits. Conditional on covariates, the estimated number of visits of respondents in the full sample who are in very poor health is about 5.8 times as large as the number of visits of those in fair health. ${ }^{17}$ Respondents with hospital stays in the preceding year go to the doctor 1.6 times as often as those without hospital stays.

Age plays an ambiguous role. In the full sample and among SHI patients, the effect is U-shaped but hardly significant, among PHI patients is highly significant and hump-shaped with a maximum at about age 50. Conditional on a visiting a doctor at all, education and income have no significant effect on the frequency of physician visits. Gerdtham (1997) reports similar results for Sweden and interprets this finding as evidence that patients' income does not affect the decisions of physicians. Marital status (in the case of men) has no effect on the frequency of visits. Thus married men contact a doctor more often than unmarried men but conditional on contact they do not visit a doctor significantly more often. Conditional on health, women visit doctors 1.2 times as often as men. Finally, being employed, full-time or part-time, reduces the frequency of doctor visits by about 10 and 7 percent respectively.

\footnotetext{
${ }^{17}$ This ratio is computed as exp[beta(very poor health)-beta(very good health)].
} 


\section{Summary and Conclusion}

In this paper I have analyzed the relationship between health insurance status, regional physician density (number of physicians per 100,000 inhabitants) and the frequency of individual doctor visits in Germany in a negative binomial hurdle model. The hurdle model statistically distinguishes between the decision to contact a physician (which is purely demand driven) and the frequency of contact decision (which combines demand and supply aspects). The paper added to earlier evidence from Germany in three respects: first, the analysis explicitly distinguishes between privately and statutorily insured patients. This distinction has proved crucial to arrive at the main finding of the paper. Conditional on health, privately insured patients are less likely to contact a physician but more frequently visit a doctor following a first contact. This finding is consistent with the idea that - if at all - physicians in Germany induce privately insured patients to demand services beyond what is strictly necessary. Physicians have an incentive to do this because patients with a private health insurance are more attractive as they can be charged higher fees for the same services.

The second innovation in this paper in comparison to earlier studies using SOEP data is that it uses an instrumental variable approach to account for the potential simultaneity of physician density. I have chosen average district gross income, the percentage of inhabitants aged 65 and over living in the district, and whether the district has a medical school as instruments. The analysis shows that these instruments perform well in explaining physician density and that they are conditionally unrelated to the main outcome variables, the probability and frequency of individual doctor visits. However, it was also shown that an instrumental variable approach is not necessary because the parameters of the instrumented variable "physician density" do not differ significantly between the ordinary hurdle model and the IV model.

Finally, the analyses combined more detailed regional data on physician density than earlier studies with individual survey data on the frequency of doctor visits. Data on doctor visits of some 20,000 individuals aged 17 to 99 were drawn from the German Socio-economic panel 2002. Regional physician density was measured on the level of districts (Kreise), of which Germany currently has 439 (the SOEP data used in this study contains information on individuals from 434 of these districts). Similar studies with SOEP data have used regional information on the state (Bundesland) level, which - due to measurement error - was probably too coarse and resulted in downward biased estimates of the effect of physician density. 
Physician density has a significant positive effect on the doctor contact probability of patients insured in the statutory health care system, whereas it has no effect on privately insured patients' contact probability. This finding can be interpreted as evidence for the idea that an increase in the number of doctors per inhabitant reduces the opportunity costs of doctor visits for statutorily insured but not for privately insured. However, the effect of physician density on the frequency of doctor visits is 1.6 times as large among privately than among statutorily insured. In fact, I find an elasticity of 27 percent that is not only statistically different from zero but also different from the contact probability elasticity.

Reverse causation and smaller opportunity costs can thus be excluded as explanations for the rising number of doctor visits of privately insured patients as physician density increases. Therefore, the findings presented in this paper give plausible albeit indirect evidence for the hypothesis that in Germany, physicians tend to induce demand for medical services among privately insured patients. 


\section{References}

Auster, R.D. \& Oaxaca, R.L. (1981): Identification of supplier induced demand in the health care sector. The Journal of Human Resources: 327-343.

Breyer, F. (1984): Die Nachfrage nach medizinischen Leistungen: Eine empirische Analyse von Daten aus der Gesetzlichen Krankenversicherung, Berlin.

Cameron, A.C. \& Trivedi, P.K. (1998): Regression Analysis of Count Data. Cambridge: Cambridge University Press.

Carlsen, F.\& Grytten, J. (1998): More Physicians: Improved Availability or Induced Demand? Health Economics 7, 495-508.

Cassel, D. \& Wilke T.. (2001): Das Saysche Gesetz im Gesundheitswesen: Schafft sich das ärztliche Leistungsangebot seine eigene Nachfrage? Zeitschrift für Gesundheitswissenschaften 9, 331-348.

Colombo, F. \& Tapay, N. (2004): Private Health Insurance in OECD Countries: The Benefits and Costs for Individuals and Health Systems. OECD Health Working Papers No 15.

Cromwell, J \& Mitchell, J.B. (1986): Physician-Induced Demand for Surgery. Journal of Health Economics 5, 293-313.

Deb, P. \& Trivedi, P. (2006): Empirical models of health care use. Ch. 14 in Jones, A. (ed.) The Elgar Companion of Health Economics. Cheltenham/Northampton: Edward Elgar.

Dranove, D. \& Wehner, P. (1994): Physician-induced demand for childbirths. Journal of Health Economics 13: 61-73.

Dullek, U \& Kerschbamer, R. (2006): On Doctors, Mechanics, and Computer Specialists: The Economics of Credence Goods. Journal of Economic Literature 44, 5-42.

Evans, R.G. (1974): Supplier Induced Demand: Some Empirical Evidence and Implications, In: Perlman, M (ed.), The Economics of Health and Medical Care, Macmillan.

Federal Office for Building and Regional Planning (BBR) (2004): Indikatoren und Karten zur Raumentwicklung 2002. CD-ROM.

Fuchs, V. (1978): The Supply of Surgeons and the Demand for Operations. Journal of Human Resources 13, 35-56

Gerdtham, U.-G. (1997): Equity in health care utilization: further tests based on hurdle models and Swedish micro data. Health Economics 6, 303-319.

Grossman, M. (2005): Education and Nonmarket Outcomes. NBER Working Paper 11582.

Gruber, J. \& Owings, M. (1996): Physician Financial Incentives and Cesarean Section Delivery. The RAND Journal of Economics, 27, 99-123.

Kassenärztliche Bundesvereinigung (2003): Grunddaten zur vertragsärztlichen Versorgung in Deutschland 2003. Downloaded Feb $12^{\text {th }} 2007$ from www.kbv.de.

Kopetsch, Thomas (2007): Arztdichte und Inanspruchnahme ärztlicher Leistungen in Deutschland: Eine empirische Untersuchung der These von der angebotsinduzierten Nachfrage nach ambulanten Arztleistungen. Schmollers Jahrbuch (forthcoming).

Krämer, W. (1981): Eine ökonometrische Untersuchung des Marktes für ambulante kassenärztliche Leistungen. Zeitschrift für die gesamte Staatswissenschaft 1, 45-61.

Manning, W.G., Morris, C.N., Newhouse, J.P. et al. (1981): A two-part model of the demand for medical care.: preliminary results from the Health Insurance Study. In: van der 
Gaag, J. \& Perlman, M. (eds.) Economics and Health Economics. Amsterdam: NorthHolland.

McCarthy, T. (1985): The Competitive Nature of the Primary-Care Physician Services Market. Journal of Health Economics 4, 93-117.

Mullahy, J. (1986): Specification and Testing of Some Modified Count Data Models. Journal of Econometrics 33, 341-365.

Mullahy, J. (1997): Instrumental-Variable Estimation of Count Data Models: Applications to Models of Cigarette Smoking Behavior. Review of Economics and Statistics 79: 586593.

Pauly, M.V. (1994): Editorial: A Re-examination of the Meaning and Importance of Supplierinduced Demand. Journal of Health Economics 13, 369-372.

Pohlmeier, W. \& Ulrich,V. (1995): An Econometric Model of the Two-Part Decision Making Process in the Demand for Health Care. Journal of Human Resources 30, 339-361.

Rice, T.D. (1983): The impact of changing Medicare reimbursement rates on physicianinduced demand. Medical Care 21, 803-815.

Rohweder, J.P. (1995): Nachfrage nach Krankenversicherung: eine Untersuchung des Wahlverhaltens der freiwillig Versicherten in Deutschland. Ph.D. Dissertation. University of Mannheim.

Stafford, R.S. (1990): Cesarean section use and source of payment: an analysis of California hospital discharge abstracts. American Journal of Public Health 80, 313-315.

Staiger, D. \& Stock, J.H. (1997): Instrumental Variables Regression with Weak Instruments. Econometrica 65: 557-586.

Stano, M. (1985): An analysis of the evidence on competition in the physician services markets. Journal of Health Economics 4, 197-211.

Sweeney, G.H. (1982): The Market for Physician's Services: Theoretical Implications and an Empirical Test of the Target Income Hypothesis. Southern Economic Journal 48, 594613

Thode, N., Bergmann, E., Kamtsiuris, P. \& Kurth, B.M. (2004): Einflussfaktoren auf die Inanspruchnahme des deutschen Gesundheitswesens und mögliche Steuerungsmechanismen. Robert-Koch Institut Berlin.

Wilensky, G.R. and Rossiter, L.R. The relative importance of physician-induced demand in the demand for medical care. Milbank Memorial Fund Quarterly/ Health and Society 61, 252-277.

Winkelmann, R. (2000): Econometric Analysis of Count Data, $3^{\text {rd }}$. ed. Berlin: Springer.

Yip, W. (1998): Physician response to Medicare fee reductions: changes in the volume of coronary artery bypass graft $(\mathrm{CABG})$ surgeries in the Medicare and private sectors. Journal of Health Economics 17, 675-699. 
Table 1: Sample description

\begin{tabular}{|c|c|c|c|c|}
\hline Variable & Mean & StdDev & Min & Max \\
\hline \multicolumn{5}{|c|}{ Individual level SHI patients $(N=19,172)$} \\
\hline \# of doctor visits & 2.57 & 4.24 & 0 & 90 \\
\hline Visited doctor & 0.69 & 0.46 & 0 & 1 \\
\hline Conditional \# of doctor visits* & 3.75 & 4.67 & 1 & 90 \\
\hline Self-rated health: very good & 0.09 & 0.28 & 0 & 1 \\
\hline Self-rated health: good & 0.40 & 0.49 & 0 & 1 \\
\hline Self-rated health: fair & 0.34 & 0.47 & 0 & 1 \\
\hline Self-rated health: poor & 0.14 & 0.34 & 0 & 1 \\
\hline Self-rated health: very poor & 0.04 & 0.19 & 0 & 1 \\
\hline Hospital stay in 2001 & 0.12 & & 0 & 1 \\
\hline Age & 47.42 & 16.91 & 17 & 99 \\
\hline Female & 0.53 & & 0 & 1 \\
\hline Married & 0.64 & & 0 & 1 \\
\hline Years of education & 11.70 & 2.42 & 7 & 18 \\
\hline Log equivalent household income & 9.79 & 0.52 & 7.53 & 13.14 \\
\hline Working full-time & 0.41 & & 0 & 1 \\
\hline Working part-time & 0.23 & & 0 & 1 \\
\hline Not working & 0.36 & & 0 & 1 \\
\hline \multicolumn{5}{|c|}{ Individual level PHI patients $(N=3,245)$} \\
\hline \# of doctor visits & 2.31 & 3.99 & 0 & 50 \\
\hline Visited doctor & 0.63 & 0.48 & 0 & 1 \\
\hline Conditional \# of doctor visits* & 3.67 & 4.50 & 1 & 50 \\
\hline Deductible & 0.40 & & 0 & 1 \\
\hline Self-rated health: very good & 0.13 & & 0 & 1 \\
\hline Self-rated health: good & 0.47 & & 0 & 1 \\
\hline Self-rated health: fair & 0.29 & & 0 & 1 \\
\hline Self-rated health: poor & 0.09 & & 0 & 1 \\
\hline Self-rated health: very poor & 0.01 & & 0 & 1 \\
\hline Hospital stay in 2001 & 0.10 & & 0 & 1 \\
\hline Age & 48.29 & 13.62 & 17 & 93 \\
\hline Female & 0.39 & & 0 & 1 \\
\hline Married & 0.72 & & 0 & 1 \\
\hline Years of education & 14.48 & 3.03 & 7 & 18 \\
\hline Log equivalent household income & 10.32 & 0.55 & 7.68 & 13.37 \\
\hline Working full-time & 0.61 & & 0 & 1 \\
\hline Working part-time & 0.18 & & 0 & 1 \\
\hline Not working & 0.21 & & 0 & 1 \\
\hline \multicolumn{5}{|l|}{ District level $(N=434)$} \\
\hline Physicians / 100,000 inhabitants & 150.4 & 51.3 & 70 & 383 \\
\hline Per capita income in $€ 10,000$ & 23.3 & 9.9 & 11.3 & 80.6 \\
\hline Percentage inhabitants aged $65+$ & 17.8 & 1.9 & 12.4 & 23.0 \\
\hline Medical school & 0.1 & & 0 & 1 \\
\hline Number of individual observations & 51.7 & 55.8 & 1 & 782 \\
\hline
\end{tabular}

* conditional on visiting; $\mathrm{N}=13,173$ (SHI), $\mathrm{N}=2,044$ (PHI) 
Table 2: First stage regression, OLS; dependent variable: log (physician density)

\begin{tabular}{|c|c|c|c|}
\hline Variable & Full sample & SHI & PHI \\
\hline \multicolumn{4}{|l|}{ Instruments (regional level variables) } \\
\hline \multirow[t]{2}{*}{ Medical school } & $0.2527 * *$ & $0.2532 * *$ & $0.2479 * *$ \\
\hline & $(0.0531)$ & $(0.0529)$ & $(0.0555)$ \\
\hline \multirow[t]{2}{*}{ Percentage of inhabitants age $65+$} & $0.0207 * *$ & $0.0208 * *$ & $0.0202 *$ \\
\hline & $(0.0075)$ & $(0.0073)$ & $(0.0095)$ \\
\hline \multirow[t]{2}{*}{ Log income per capita } & $0.4575 * *$ & $0.4573 * *$ & $0.4612 * *$ \\
\hline & $(0.0470)$ & $(0.0461)$ & $(0.0555)$ \\
\hline \multicolumn{4}{|l|}{ Individual level variables } \\
\hline \multirow[t]{2}{*}{ PHI } & 0.0075 & & \\
\hline & $(0.0071)$ & & \\
\hline \multirow[t]{2}{*}{ Deductible } & -0.0025 & & -0.0020 \\
\hline & $(0.0068)$ & & $(0.0071)$ \\
\hline \multirow[t]{2}{*}{ Very good health } & 0.0030 & 0.0009 & 0.0125 \\
\hline & $(0.0083)$ & $(0.0078)$ & $(0.0156)$ \\
\hline \multirow[t]{2}{*}{ Good health } & 0.0007 & -0.0018 & 0.0143 \\
\hline & $(0.0044)$ & $(0.0045)$ & $(0.0077)$ \\
\hline \multirow[t]{2}{*}{ Poor health } & 0.0017 & 0.0019 & -0.0021 \\
\hline & $(0.0036)$ & $(0.0039)$ & $(0.0135)$ \\
\hline \multirow[t]{2}{*}{ Very poor health } & 0.0027 & -0.0003 & 0.0367 \\
\hline & $(0.0076)$ & $(0.0080)$ & $(0.0278)$ \\
\hline \multirow[t]{2}{*}{ Hospital stay in 2001} & 0.0064 & 0.0078 & -0.0019 \\
\hline & $(0.0041)$ & $(0.0040)$ & $(0.0130)$ \\
\hline \multirow[t]{2}{*}{ Age } & 0.0007 & 0.0008 & 0.0001 \\
\hline & $(0.0006)$ & $(0.0007)$ & $(0.0016)$ \\
\hline \multirow[t]{2}{*}{$(\text { Age } / 10)^{\wedge} 2$} & -0.0004 & -0.0003 & 0.0001 \\
\hline & $(0.0006)$ & $(0.0007)$ & $(0.0016)$ \\
\hline \multirow[t]{2}{*}{ Female } & 0.0020 & 0.0032 & -0.0129 \\
\hline & $(0.0033)$ & $(0.0036)$ & $(0.0141)$ \\
\hline \multirow[t]{2}{*}{ Married } & $-0.0220 * *$ & $-0.0235^{* *}$ & -0.0151 \\
\hline & $(0.0061)$ & $(0.0068)$ & $(0.0087)$ \\
\hline \multirow{2}{*}{ Married*Female } & 0.0041 & 0.0035 & 0.0209 \\
\hline & $(0.0036)$ & $(0.0043)$ & $(0.0170)$ \\
\hline \multirow[t]{2}{*}{ Years of Education } & $0.0061 * *$ & $0.0072 * *$ & 0.0025 \\
\hline & $(0.0011)$ & $(0.0012)$ & $(0.0013)$ \\
\hline \multirow[t]{2}{*}{ Log equivalent hh income } & $-0.0152 * *$ & $-0.0165 * *$ & -0.0106 \\
\hline & $(0.0058)$ & $(0.0059)$ & $(0.0109)$ \\
\hline \multirow[t]{2}{*}{ Full Time Employed } & 0.0048 & 0.0056 & 0.0054 \\
\hline & $(0.0037)$ & $(0.0039)$ & $(0.0100)$ \\
\hline \multirow[t]{2}{*}{ Part Time Employed } & 0.0014 & 0.0008 & 0.0098 \\
\hline & $(0.0037)$ & $(0.0041)$ & $(0.0098)$ \\
\hline \multirow[t]{2}{*}{ Constant } & $3.2074 * *$ & $3.2060 * *$ & $3.2261 * *$ \\
\hline & $(0.2383)$ & $(0.2339)$ & $(0.2856)$ \\
\hline $\mathrm{N}$ & 22,417 & 19,172 & 3,245 \\
\hline Clusters & 434 & 433 & 394 \\
\hline F statistic instruments & 70.37 & 73.31 & 55.40 \\
\hline$\Delta \mathrm{R}^{2}$ from including instruments & 0.62 & 0.62 & 0.62 \\
\hline
\end{tabular}

Note: ${ }^{*} \mathrm{p}<0.05 ; * * \mathrm{p}<0.01$ 
Table 3. Logit regressions explaining whether a doctor was visited at all in last three months

\begin{tabular}{|c|c|c|c|c|c|c|}
\hline & \multicolumn{2}{|c|}{ Full sample } & \multicolumn{2}{|c|}{ SHI sample } & \multicolumn{2}{|l|}{ PHI sample } \\
\hline & $\begin{array}{l}\text { Logit } \\
\text { (1) }\end{array}$ & $\begin{array}{l}\text { IV-Logit }{ }^{a)} \\
\text { (2) }\end{array}$ & $\begin{array}{l}\text { Logit } \\
\text { (3) }\end{array}$ & $\begin{array}{l}\text { IV-Logit }{ }^{a)} \\
\text { (4) }\end{array}$ & $\begin{array}{l}\text { Logit } \\
(5)\end{array}$ & $\begin{array}{l}\text { IV-Logit }{ }^{\mathrm{a})} \\
\text { (6) }\end{array}$ \\
\hline Log (Physician Density) & $\begin{array}{l}0.1488^{* *} \\
(0.0537)\end{array}$ & $\begin{array}{l}0.1297 \\
(0.0685)\end{array}$ & $\begin{array}{l}0.1769^{* *} \\
(0.0595)\end{array}$ & $\begin{array}{l}0.1661^{*} \\
(0.0749)\end{array}$ & $\begin{array}{l}-0.0045 \\
(0.1258)\end{array}$ & $\begin{array}{l}-0.0357 \\
(0.1620)\end{array}$ \\
\hline PHI & $\begin{array}{l}-0.1824 * * \\
(0.0568)\end{array}$ & $\begin{array}{l}-0.1812 * * \\
(0.0558)\end{array}$ & & & & \\
\hline Deductible & $\begin{array}{l}-0.0704 \\
(0.0797)\end{array}$ & $\begin{array}{l}-0.0706 \\
(0.0814)\end{array}$ & & & $\begin{array}{l}-0.0618 \\
(0.0818)\end{array}$ & $\begin{array}{l}-0.0615 \\
(0.0877)\end{array}$ \\
\hline Very good health & $\begin{array}{l}-1.2303 * * \\
(0.0556)\end{array}$ & $\begin{array}{l}-1.2292 * * \\
(0.0568)\end{array}$ & $\begin{array}{l}-1.2650 * * \\
(0.0618)\end{array}$ & $\begin{array}{l}-1.2642 * * \\
(0.0595)\end{array}$ & $\begin{array}{l}-1.0799 * * \\
(0.1281)\end{array}$ & $\begin{array}{l}-1.0781 * * \\
(0.1282)\end{array}$ \\
\hline Good health & $\begin{array}{l}-0.6696^{* *} \\
(0.0364)\end{array}$ & $\begin{array}{l}-0.6693 * * \\
(0.0372)\end{array}$ & $\begin{array}{l}-0.6755^{* *} \\
(0.0397)\end{array}$ & $\begin{array}{l}-0.6753 * * \\
(0.0391)\end{array}$ & $\begin{array}{l}-0.6266^{* *} \\
(0.0924)\end{array}$ & $\begin{array}{l}-0.6258^{* *} \\
(0.0986)\end{array}$ \\
\hline Fair health (reference category) & 0.0000 & 0.0000 & 0.0000 & 0.0000 & 0.0000 & 0.0000 \\
\hline Poor health & $\begin{array}{l}0.9555^{* *} \\
(0.0699)\end{array}$ & $\begin{array}{l}0.9554 * * \\
(0.0756)\end{array}$ & $\begin{array}{l}0.9560 * * \\
(0.0744)\end{array}$ & $\begin{array}{l}0.9558 * * \\
(0.0751)\end{array}$ & $\begin{array}{l}0.9661 * * \\
(0.2052)\end{array}$ & $\begin{array}{l}0.9669 * * \\
(0.2208)\end{array}$ \\
\hline Very poor health & $\begin{array}{l}1.5025^{* *} \\
(0.1742)\end{array}$ & $\begin{array}{l}1.5016^{* *} \\
(0.1727)\end{array}$ & $\begin{array}{l}1.5102 * * \\
(0.1818)\end{array}$ & $\begin{array}{l}1.5088^{* *} \\
(0.1730)\end{array}$ & $\begin{array}{l}1.3561^{*} \\
(0.6139)\end{array}$ & $\begin{array}{l}1.3584^{*} \\
(0.6338)\end{array}$ \\
\hline Hospital stay in 2001 & $\begin{array}{l}0.9364 * * \\
(0.0640)\end{array}$ & $\begin{array}{l}0.9364^{* *} \\
(0.0612)\end{array}$ & $\begin{array}{l}0.9225^{* *} \\
(0.0692)\end{array}$ & $\begin{array}{l}0.9226^{* *} \\
(0.0639)\end{array}$ & $\begin{array}{l}1.0479 * * \\
(0.1699)\end{array}$ & $\begin{array}{l}1.0479 * * \\
(0.1736)\end{array}$ \\
\hline Age & $\begin{array}{l}-0.0589 * * \\
(0.0069)\end{array}$ & $\begin{array}{l}-0.0588 * * \\
(0.0067)\end{array}$ & $\begin{array}{l}-0.0630 * * \\
(0.0074)\end{array}$ & $\begin{array}{l}-0.0629 * * \\
(0.0070)\end{array}$ & $\begin{array}{l}-0.0428^{*} \\
(0.0211)\end{array}$ & $\begin{array}{l}-0.0428 \\
(0.0224)\end{array}$ \\
\hline$(\text { Age } / 10)^{\wedge} 2$ & $\begin{array}{l}0.0769 * * \\
(0.0074)\end{array}$ & $\begin{array}{l}0.0768 * * \\
(0.0075)\end{array}$ & $\begin{array}{l}0.0829 * * \\
(0.0079)\end{array}$ & $\begin{array}{l}0.0829 * * \\
(0.0077)\end{array}$ & $\begin{array}{l}0.0495^{*} \\
(0.0219)\end{array}$ & $\begin{array}{l}0.0495^{*} \\
(0.0238)\end{array}$ \\
\hline Female & $\begin{array}{l}0.6515 * * \\
(0.0523)\end{array}$ & $\begin{array}{l}0.6520 * * \\
(0.0533)\end{array}$ & $\begin{array}{l}0.6606 * * \\
(0.0561)\end{array}$ & $\begin{array}{l}0.6612 * * \\
(0.0534)\end{array}$ & $\begin{array}{l}0.5684 * * \\
(0.1501)\end{array}$ & $\begin{array}{l}0.5687 * * \\
(0.1557)\end{array}$ \\
\hline Married & $\begin{array}{l}0.1661 * * \\
(0.0492)\end{array}$ & $\begin{array}{l}0.1649 * * \\
(0.0497)\end{array}$ & $\begin{array}{l}0.1540 * * \\
(0.0546)\end{array}$ & $\begin{array}{l}0.1531 * * \\
(0.0495)\end{array}$ & $\begin{array}{l}0.2285^{*} \\
(0.1140)\end{array}$ & $\begin{array}{l}0.2265 \\
(0.1171)\end{array}$ \\
\hline Married*Female & $\begin{array}{l}-0.1315^{*} \\
(0.0671)\end{array}$ & $\begin{array}{l}-0.1321^{*} \\
(0.0668)\end{array}$ & $\begin{array}{l}-0.1265 \\
(0.0727)\end{array}$ & $\begin{array}{l}-0.1271 \\
(0.0686)\end{array}$ & $\begin{array}{l}-0.0907 \\
(0.1832)\end{array}$ & $\begin{array}{l}-0.0901 \\
(0.1878)\end{array}$ \\
\hline Years of Education & $\begin{array}{l}0.0493 * * \\
(0.0066)\end{array}$ & $\begin{array}{l}0.0495 * * \\
(0.0070)\end{array}$ & $\begin{array}{l}0.0575^{* *} \\
(0.0076)\end{array}$ & $\begin{array}{l}0.0576 * * \\
(0.0079)\end{array}$ & $\begin{array}{l}0.0291^{*} \\
(0.0139)\end{array}$ & $\begin{array}{l}0.0294^{*} \\
(0.0140)\end{array}$ \\
\hline Log equivalent hh income & $\begin{array}{l}0.1829 * * \\
(0.0332)\end{array}$ & $\begin{array}{l}0.1832 * * \\
(0.0354)\end{array}$ & $\begin{array}{l}0.1866 * * \\
(0.0368)\end{array}$ & $\begin{array}{l}0.1867^{* *} \\
(0.0390)\end{array}$ & $\begin{array}{l}0.1676^{*} \\
(0.0779)\end{array}$ & $\begin{array}{l}0.1686^{*} \\
(0.0820)\end{array}$ \\
\hline Full Time Employed & $\begin{array}{l}-0.1305^{* *} \\
(0.0486)\end{array}$ & $\begin{array}{l}-0.1308^{* *} \\
(0.0499)\end{array}$ & $\begin{array}{l}-0.1187^{*} \\
(0.0523)\end{array}$ & $\begin{array}{l}-0.1188^{*} \\
(0.0536)\end{array}$ & $\begin{array}{l}-0.1283 \\
(0.1371)\end{array}$ & $\begin{array}{l}-0.1286 \\
(0.1417)\end{array}$ \\
\hline Part Time Employed & $\begin{array}{l}-0.0514 \\
(0.0491)\end{array}$ & $\begin{array}{l}-0.0514 \\
(0.0506)\end{array}$ & $\begin{array}{l}-0.0697 \\
(0.0524)\end{array}$ & $\begin{array}{l}-0.0696 \\
(0.0545)\end{array}$ & $\begin{array}{l}0.1671 \\
(0.1435)\end{array}$ & $\begin{array}{l}0.1671 \\
(0.1406)\end{array}$ \\
\hline Constant & $\begin{array}{l}-1.5429 * * \\
(0.4146)\end{array}$ & $\begin{array}{l}-1.4550^{* *} \\
(0.4885)\end{array}$ & $\begin{array}{l}-1.7592 * * \\
(0.4579)\end{array}$ & $\begin{array}{l}-1.7087 * * \\
(0.5282)\end{array}$ & $\begin{array}{l}-0.7254 \\
(1.0202)\end{array}$ & $\begin{array}{l}-0.5830 \\
(1.2509)\end{array}$ \\
\hline $\mathrm{N}$ & 22,417 & 22,417 & 19,172 & 19,172 & 3,245 & 3,245 \\
\hline Model Chi-Squared & 3448.43 & 3444.48 & 3057.30 & 3053.42 & 380.94 & 380.99 \\
\hline Pseudo-R2 & 0.1225 & 0.1224 & 0.1283 & 0.1282 & 0.0891 & 0.0891 \\
\hline P-value of Hausman endogenity test & .83 & & .91 & & .88 & \\
\hline
\end{tabular}

Note: a) Standard errors are bootstrapped (200 reps), ${ }^{*} \mathrm{p}<0.05,{ }^{* *} \mathrm{p}<0.01$ 
Table 4: Zero-truncated negative binomial regressions explaining the number of doctor visits in last three months

\begin{tabular}{|c|c|c|c|c|c|c|}
\hline & \multicolumn{2}{|l|}{ Full sample } & \multicolumn{2}{|l|}{ SHI sample } & \multicolumn{2}{|l|}{ PHI sample } \\
\hline & Zero- & IV-Zero & Zero- & IV-Zero & Zero- & IV-Zero \\
\hline & Truncated & Truncated & Truncated & Truncated & Truncated & Truncated \\
\hline & Negbin & Negbin ${ }^{a)}$ & Negbin & Negbin ${ }^{a}$ & Negbin & Negbin ${ }^{a)}$ \\
\hline \multirow[t]{2}{*}{ Log (Physician Density) } & $0.1719 * *$ & $0.2112 * *$ & $0.1647 * *$ & $0.2047 * *$ & $0.2702 * *$ & $0.3049 *$ \\
\hline & $(0.0344)$ & $(0.0532)$ & $(0.0367)$ & $(0.0572)$ & $(0.0993)$ & $(0.1449)$ \\
\hline \multirow[t]{2}{*}{ PHI } & $0.1816^{* *}$ & $0.1787 * *$ & & & & \\
\hline & $(0.0384)$ & $(0.0437)$ & & & & \\
\hline \multirow[t]{2}{*}{ Deductible } & -0.0800 & -0.0798 & & & -0.0959 & -0.0956 \\
\hline & $(0.0564)$ & $(0.0746)$ & & & $(0.0639)$ & $(0.0781)$ \\
\hline \multirow[t]{2}{*}{ Very good health } & $-0.7109 * *$ & $-0.7110 * *$ & $-0.6633 * *$ & $-0.6636^{* *}$ & $-0.8792 * *$ & $-0.8777 * *$ \\
\hline & $(0.0495)$ & $(0.0662)$ & $(0.0546)$ & $(0.0821)$ & $(0.1199)$ & $(0.1295)$ \\
\hline \multirow[t]{2}{*}{ Good health } & $-0.5237 * *$ & $-0.5232 * *$ & $-0.5225 * *$ & $-0.5216^{* *}$ & $-0.5289 * *$ & $-0.5311 * *$ \\
\hline & $(0.0252)$ & $(0.0310)$ & $(0.0271)$ & $(0.0340)$ & $(0.0694)$ & $(0.0844)$ \\
\hline Fair health (reference category) & 0.0000 & 0.0000 & 0.0000 & 0.0000 & 0.0000 & 0.0000 \\
\hline \multirow[t]{2}{*}{ Poor health } & $0.6070 * *$ & $0.6076^{* *}$ & $0.5874 * *$ & $0.5883 * *$ & $0.7961 * *$ & $0.7935 * *$ \\
\hline & $(0.0277)$ & $(0.0305)$ & $(0.0289)$ & $(0.0327)$ & $(0.0934)$ & $(0.1031)$ \\
\hline \multirow[t]{2}{*}{ Very poor health } & $1.0452 * *$ & $1.0395 * *$ & $1.0486 * *$ & $1.0432 * *$ & $0.9573 * *$ & $0.9518^{* *}$ \\
\hline & $(0.0449)$ & $(0.0484)$ & $(0.0456)$ & $(0.0579)$ & $(0.2021)$ & $(0.2324)$ \\
\hline \multirow{2}{*}{ Hospital stay in 2001} & $0.5093 * *$ & $0.5098 * *$ & $0.5045 * *$ & $0.5047 * *$ & $0.5404 * *$ & $0.5435 * *$ \\
\hline & $(0.0266)$ & $(0.0301)$ & $(0.0279)$ & $(0.0334)$ & $(0.0835)$ & $(0.0946)$ \\
\hline \multirow[t]{2}{*}{ Age } & -0.0053 & -0.0053 & $-0.0098 *$ & -0.0098 & $0.0499 * *$ & $0.0492 * *$ \\
\hline & $(0.0039)$ & $(0.0048)$ & $(0.0040)$ & $(0.0052)$ & $(0.0139)$ & $(0.0159)$ \\
\hline \multirow{2}{*}{$(\text { Age } / 10)^{\wedge} 2$} & 0.0033 & 0.0034 & 0.0075 & 0.0075 & $-0.0490 * *$ & $-0.0482 * *$ \\
\hline & $(0.0038)$ & $(0.0047)$ & $(0.0039)$ & $(0.0051)$ & $(0.0137)$ & $(0.0155)$ \\
\hline \multirow[t]{2}{*}{ Female } & $0.1986^{* *}$ & $0.1945^{* *}$ & $0.1966 * *$ & $0.1919 * *$ & $0.2630^{*}$ & $0.2642 *$ \\
\hline & $(0.0362)$ & $(0.0445)$ & $(0.0381)$ & $(0.0516)$ & $(0.1185)$ & $(0.1298)$ \\
\hline \multirow[t]{2}{*}{ Married } & 0.0473 & 0.0479 & 0.0618 & 0.0622 & -0.0292 & -0.0280 \\
\hline & $(0.0358)$ & $(0.0421)$ & $(0.0386)$ & $(0.0477)$ & $(0.0969)$ & $(0.1183)$ \\
\hline \multirow[t]{2}{*}{ Married*Female } & $-0.0996^{*}$ & -0.0963 & $-0.1087 *$ & -0.1048 & -0.1319 & -0.1337 \\
\hline & $(0.0448)$ & $(0.0519)$ & $(0.0476)$ & $(0.0612)$ & $(0.1388)$ & $(0.1542)$ \\
\hline \multirow[t]{2}{*}{ Years of Education } & 0.0025 & 0.0022 & 0.0023 & 0.0019 & 0.0003 & 0.0004 \\
\hline & $(0.0043)$ & $(0.0051)$ & $(0.0048)$ & $(0.0062)$ & $(0.0106)$ & $(0.0131)$ \\
\hline \multirow[t]{2}{*}{ Log equivalent hh income } & 0.0022 & 0.0016 & 0.0169 & 0.0163 & -0.1076 & -0.1063 \\
\hline & $(0.0215)$ & $(0.0256)$ & $(0.0227)$ & $(0.0266)$ & $(0.0637)$ & $(0.0733)$ \\
\hline \multirow[t]{2}{*}{ Full Time Employed } & $-0.1055^{* *}$ & $-0.1049 * *$ & $-0.1056^{* *}$ & $-0.1048^{*}$ & -0.1858 & -0.1851 \\
\hline & $(0.0306)$ & $(0.0379)$ & $(0.0323)$ & $(0.0419)$ & $(0.0957)$ & $(0.1135)$ \\
\hline \multirow[t]{2}{*}{ Part Time Employed } & $-0.0725^{*}$ & -0.0725 & $-0.0784 *$ & $-0.0784^{*}$ & -0.0742 & -0.0754 \\
\hline & $(0.0307)$ & $(0.0380)$ & $(0.0322)$ & $(0.0395)$ & $(0.1006)$ & $(0.1106)$ \\
\hline \multirow[t]{2}{*}{ Constant } & -0.0021 & -0.1872 & 0.0117 & -0.1765 & -0.5345 & -0.7117 \\
\hline & $(0.2646)$ & $(0.3706)$ & $(0.2813)$ & $(0.3825)$ & $(0.8067)$ & $(0.9403)$ \\
\hline Ln(alpha) & 0.0550 & 0.0537 & 0.0098 & 0.0083 & $0.3206 * *$ & $0.3217 * *$ \\
\hline & $(0.0336)$ & $(0.0497)$ & $(0.0355)$ & $(0.0552)$ & $(0.1042)$ & $(0.1215)$ \\
\hline $\mathrm{N}$ & 15,219 & 15,219 & 13,175 & 13,175 & 2,044 & 2,044 \\
\hline Model Chi-Squared & 3190.92 & 3190.40 & 2810.94 & 2810.69 & 413.75 & 412.30 \\
\hline Pseudo-R2 & 0.0488 & 0.0488 & 0.0495 & 0.0495 & 0.0488 & 0.0477 \\
\hline P-value of Hausman endogenity test & .54 & & .56 & & .84 & \\
\hline
\end{tabular}

Note: a) Standard errors are bootstrapped (200 reps), ${ }^{*} \mathrm{p}<0.05, * * \mathrm{p}<0.01$ 


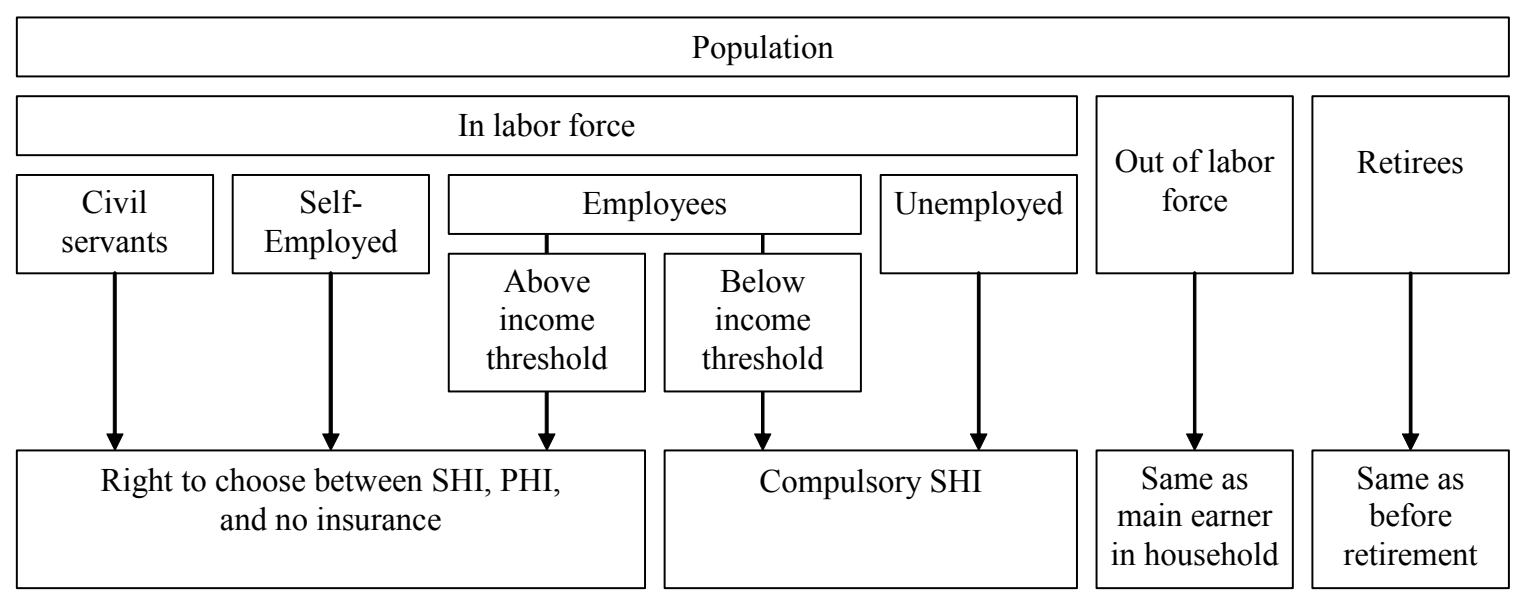

Figure 1: Stylised description of the German health insurance system

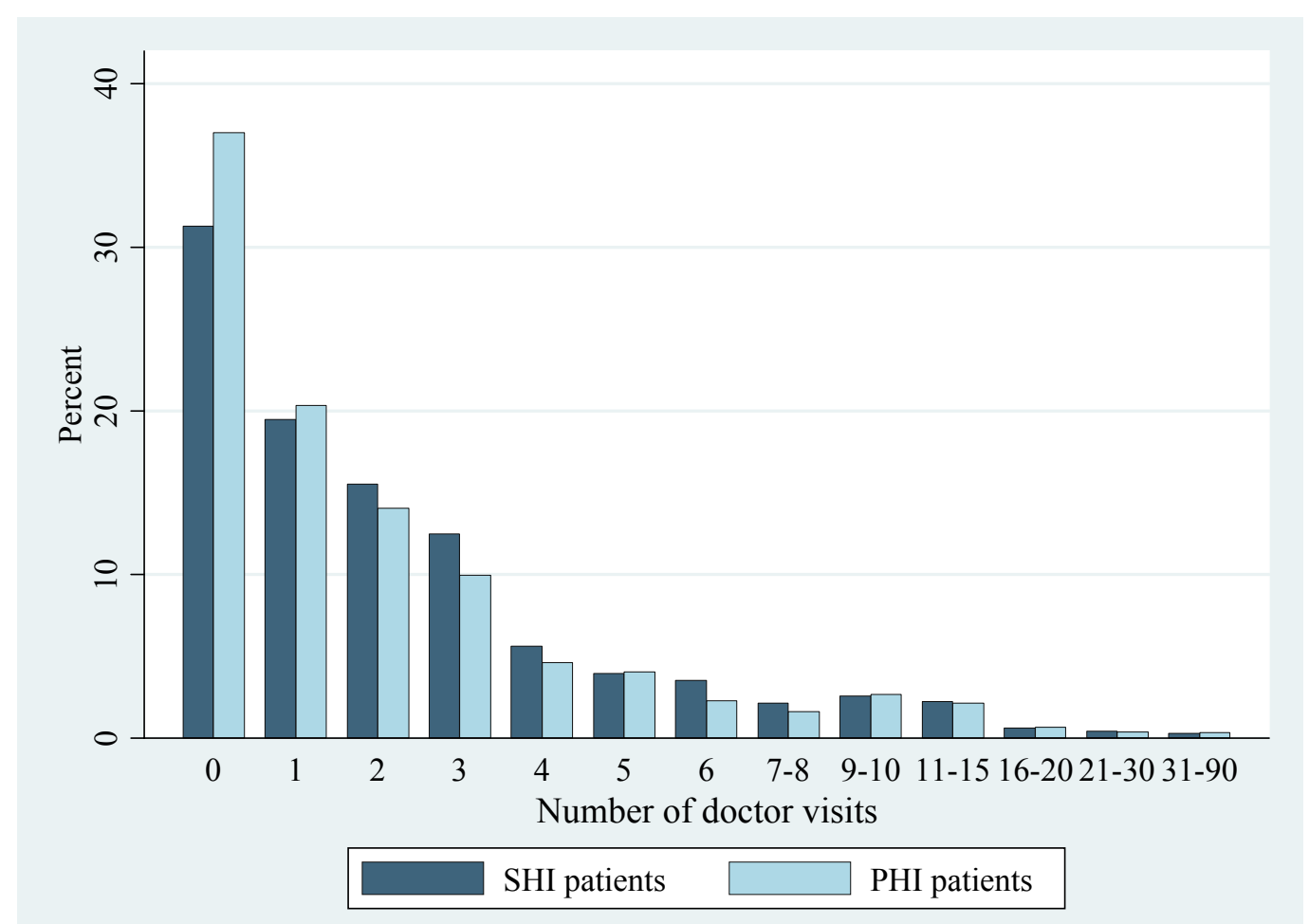

Figure 2: Individual number of doctor visits in the last three months (SOEP 2002), by insurance status 


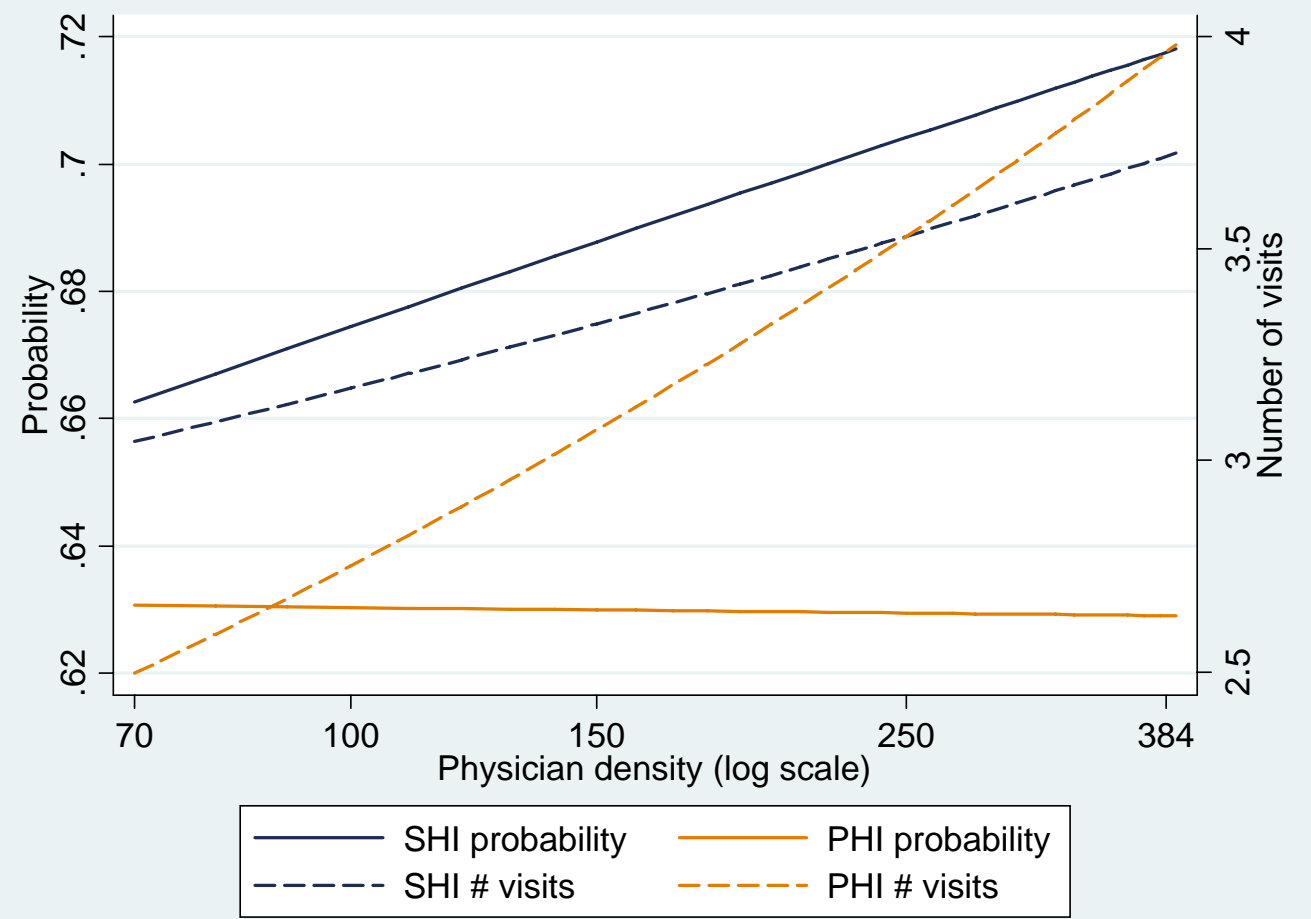

Figure 3: Average predicted probability and average conditional number of doctor visits in the last three months (SOEP 2002), by physician density and insurance status. Predictions are based on Table 4, columns 3 and 5 and Table 5, columns 3 and 5 


\section{Discussion Paper Series}

Mannheim Research Institute for the Economics of Aging Universität Mannheim

To order copies, please direct your request to the author of the title in question.

\begin{tabular}{|c|c|c|c|}
\hline Nr. & Autoren & Titel & Jahr \\
\hline $107-06$ & Barbara Berkel & $\begin{array}{l}\text { Retirement Age and Preretirement in German } \\
\text { Administrative Data }\end{array}$ & 06 \\
\hline $108-06$ & $\begin{array}{l}\text { Hans-Martin von } \\
\text { Gaudecker } \\
\text { Carsten Weber }\end{array}$ & $\begin{array}{l}\text { Mandatory Unisex Policies and Annuity Pricing: } \\
\text { Quasi-Experimental Evidence from Germany }\end{array}$ & 06 \\
\hline $109-06$ & Daniel Schunk & $\begin{array}{l}\text { The German SAVE Survey: Documentation and } \\
\text { Methodology }\end{array}$ & 06 \\
\hline $110-06$ & Barbara Berkel & $\begin{array}{l}\text { THE EMU and German Cross Border Portfolio } \\
\text { Flows }\end{array}$ & 06 \\
\hline $111-06$ & Martin Salm & $\begin{array}{l}\text { Can subjective mortality expectations and stated } \\
\text { preferences explain varying consumption and } \\
\text { saving behaviors among the elderly? }\end{array}$ & 06 \\
\hline $112-06$ & $\begin{array}{l}\text { Daniel Houser, } \\
\text { Daniel Schunk, } \\
\text { Joachim Winter }\end{array}$ & Trust Games Measure Trust & 06 \\
\hline $113-06$ & $\begin{array}{l}\text { Hanming Fang, } \\
\text { Michael Keane, } \\
\text { Ahmed Khwaja, } \\
\text { Martin Salm, } \\
\text { Dan Silverman }\end{array}$ & $\begin{array}{l}\text { Testing the Mechanisms of Structural Models: } \\
\text { The Case of the Mickey Mantle Effect }\end{array}$ & 06 \\
\hline $114-06$ & $\begin{array}{l}\text { Axel Börsch-Supan, } \\
\text { Anette Reil-Held, } \\
\text { Daniel Schunk }\end{array}$ & $\begin{array}{l}\text { Das Sparverhalten deutscher Haushalte: Erste } \\
\text { Erfahrungen mit der Riester-Rente }\end{array}$ & 06 \\
\hline $115-07$ & $\begin{array}{l}\text { Karsten Hank, } \\
\text { Barbara Schaan }\end{array}$ & $\begin{array}{l}\text { Cross-National Variations in the Correlation } \\
\text { between Frequency of Prayer and Health } \\
\text { among Older Europeans }\end{array}$ & 07 \\
\hline $116-07$ & Stephanie Stuck & $\begin{array}{l}\text { Informelle Arbeit älterer Frauen und Männer in } \\
\text { Europa }\end{array}$ & 07 \\
\hline $117-07$ & & & 07 \\
\hline $118-07$ & Martin Salm & $\begin{array}{l}\text { The Effect of Pensions on Longevity: Evidence } \\
\text { from Union Army Veterans }\end{array}$ & 07 \\
\hline $119-07$ & Hendrik Jürges & $\begin{array}{l}\text { Health insurance status and physician-induced } \\
\text { demand for medical services in Germany: new } \\
\text { evidence from combined district and individual } \\
\text { level data }\end{array}$ & 07 \\
\hline
\end{tabular}

